The conference approved these proposals, and placed particular emphasis on its endorsement of the statement by the education minister that the criterion for any change-over decision should be an improvement in standards.

\section{Broadcasting Abroad}

LARGELY at the initiative of the Ford Foundation, plans are being canvassed for the setting up of an International Broadcasting Institute intended to ensure that the fullest use is made of technical innova. tions such as Earth satellites. The institute has a distinguished backing, with sponsors such as Dr J. Wiesner in the United States, and Mr Kenneth Younger and Professor Asa Briggs in the United Kingdom. A draft constitution is now circulating, and was indeed discussed in detail at a meeting in New York two weeks ago. The immediate problem is to find financial support for the enterprise, and several foundations have already been approached. To begin with, the institute might consist of a director supported by a small office staff and with a brief to define the field in which a more fully equipped institute might operate. For several reasons, one of which is that non-profit organizations are well treated by the taxation authorities in the United Kingdom, the official headquarters of the institute are likely to be in London.

For the time being, at least, the nucleus of the new institute thinks of itself more as a research organization than a pressure group. It would tackle a variety of problems, such as the way in which broadcasting (principally of television) might be used to provide educational services for developing countries and the legal questions which might arise in broadcasting from one country to another, possibly by means of satellites. Whether the institute would try to engage directly in the issue of just how the new international agreement for INTELSAT should be negotiated is another problem. It also remains to be seen how the institute will be able to define its relationships with bodies, official and otherwise, already operating in this field. Broadcasting networks in Britain and the United States seem to be cool but not hostile.

\section{Social Medicine}

THE only research unit of the Medical Research Council devoted to social medicine is just settling down in its new quarters at the London School of Hygiene and Tropical Medicine. Professor J. N. Morris, formerly the director, becomes honorary director of the unit on his appointment to the chair of public health in the University of London. The unit, consisting of a staff of eleven doctors, statisticians and social scientists as well as clerical staff, moves with him.

Three main topics are being investigated by the unit, which is using the same general methods of statistical analysis, individual and clinical studies for each. Heart disease, particularly coronary thrombosis, has been under examination for about twenty years, with three aims in view: first to discover causes, secondly to find individuals who might be particularly susceptible, and finally to attempt to reduce the risks for these individuals. Using the discovery that high cholesterol levels in the blood point to thrombosis, experiments are being carried out to see if lowering these lipid levels in the blood reduces the incidence of thrombosis among otherwise healthy people. Trial groups in Edinburgh, Prague and Budapest are cooperating in this project. A study is about to be made of men in the civil service to see what effects exercise may have on the incidence of thrombosis. The unit has already established that occupational exercise has a protective value.

In its former home in the East End of London the unit involved itself in local affairs by beginning a survey of juvenile delinquency in that area. No obvious conclusions could be drawn from variations in housing backgrounds, and apparently similar schools produced widely differing delinquency rates. Attitudes within the schools may play an important part, but have yet to be studied. It is hoped that statistical and clinical analyses will lead eventually to a reasonably simple test that can be used by magistrates and probation officers to discover the likelihood of a first offender becoming one of the hard core of delinquents.

Operational research into various aspects of the Health Service forms the third activity of the unit. At present the quality and effectiveness of medical care in different types of hospital are being assessed. Why is it, for example, that teaching hospitals are more effective than others? In this field of everyday medicine it is important to discover causes for variations in the success rates, and a large scale survey of prostate treatment is now being made.

\section{Connective Tissue Clubs Connected}

At the joint meeting of the French and British micropolysaccharide clubs, held on September 29 at the Institut Pasteur, Dr Robert, the secretary of the French. club which initiated this first joint international meeting, proposed that a European Federation of Connective Tissue Clubs should be formed. This was agreed: Professor Kuhn of Munich pledged West German participation. Under the federation the existing national clubs will of course retain their identity and local interests, as well as participate in international meetings. This arrangement should improve on the present situation in which European workers meet each other, if at all, as visitors in the USA. Discussions are now under way in the hope that the return AngloFrench meeting in 1968 , to be held in Britain, will be the first full meeting of the new federation.

At the Paris meeting the magnificent hospitality of Professor Delaunay and the French club provided a perfect background for much productive discussion. Seventeen communications, two of them full lectures by Dr J. T. Dingle and Professor J. Montreuil, wer: given during the day, on the chemistry, metabolism. morphology, embryology and pathology of connective tissue and its components.

The federation, by arranging regular international meetings, should provide new impetus for the European biochemists, pathologists, electron microscopists and many others involved in the expanding field of connective tissue research.

\section{Human Physiology}

THe National Institute for Medical Research seems particularly anxious to make known its work on the 
physiology of normal man and the application of its results in industry and the services. A number of interesting and varied projects are currently in progress at the laboratories. In the Department of Human Biomechanics, for example, R. J. Whitney is studying movements of normal people. Photography is used for an exact analysis of the motion of different parts of the body, and the presence or absence of activity in specific muscles which may be involved in the motion is registered by electromyography. One experiment, completed nine months ago, was concerned with the effects of prohibition of movement on physiological and psychological activities of man. Several subjects under thirty were examined in four types of sitting positions varying from supine to upright during twenty-four hours of confinement. Among the changes recorded were EMG of limbs, heart pulse and posture change. A time lapse film indicated that principal movement of the head and feet occurred during the twenty-four hours. Although the results are difficult to analyse, there is evidence of a definite diurnal rhythm in temperature and in swelling of the ankles.

The function of the Division of Biomedical Engineering is to establish a link between modern technology and human biology. It has designed SAMI (Socially Acceptable Monitoring Instrument) to investigate "normal man leading a normal life". This heart beat counter, which derives its input signal from two adhesive chest electrodes, can store acquired information for prolonged periods by means of a reversible electrochemical integrator. Using SAMI, emotional stress has been measured in airline pilots, pregnant women, Peruvian women and schoolchildren. SAMI can also be used to estimate human activity and in clinical follow-up and in work study. A temperature SAMI is also becoming available and SAMIs for noise and posture are in preparation. The development of FAIR (Fast Access Information Retrieval) in the department should lead to full-text, special subject collections becoming available on a user's desk, together with a retrieval system which allows one to generate highly specific subject headings. By providing a list of key words for coding documents, it is hoped that a larger scientific population will consult literature sources of information.

Another interesting study at the laboratories is the investigation of anaemia during pregnancy in immigrant mothers with abnormal haemoglobins and thalassaemia. In the heterozygous conditions, these are both clinically mild but become more severe during increased physiological stress. The traits can be identified by starch-gel electrophoresis and treated with iron administered orally. In 1966 a Tristan da Cunha working party was set up through the council, to investigate the health of the islanders and to assess the balance of their diets. Results indicated that the islanders do not, in fact, live up to their reputation for good health.

\section{Food Additives}

THE use of food additives is difficult to control satisfactorily, for although many countries have agencies and scientific institutions with this special responsibility, others lack adequate facilities. The problem is being dealt with by a joint $\mathrm{FAO} / \mathrm{WHO}$ programme which aims to make systematic evaluations of food additives and to provide evidence to member states of FAO and WHO. The programme is implemented by the joint $\mathrm{FAO} / \mathrm{WHO}$ Expert Committee on Food Additives which advises the Codex Committee on Food Additives, which in turn, through the Codex Alimentarius Commission, proposes to governments internationally acceptable tolerances for additives in various foods.

The Codex Committee selects the substances to be considered by the Expert Committee, whose terms of reference are to establish specifications for identity and purity for food additives and to evaluate toxicological data. It also recommends, if possible, acceptable daily intakes for man. This committee has just produced its tenth report, on "Some Emulsifiers and Stabilizers and Certain Other Substances" (WHO Technical Report Series, No. 373; 1967). The committee recommends that biochemical and metabolic studies be substituted sometimes for the more usual toxicological studies when the effects of food additives are evaluated. If the additive is completely broken. down in normal metabolism to common dietary or body constituents, toxicological investigation is a wasted effort, for the additives are then behaving like foods. For such cases an acceptable daily intake has been calculated such that the additive should not increase the food component into which it is converted by more than about 5 per cent of the amount in an average diet. The fatty emulsifiers such as acetic, citric and lactic acid and fatty acid esters of glycerol are in this category, for in metabolism they are all hydrolysed to acceptable dietary constituents.

The committee says that toxic concentrations of arsenic, lead or heavy metals are unlikely to be found in food now, but it gives specifications to encourage the use of good quality raw materials and equipment. Most normal diets probably supply $1 \cdot 5-2 \cdot 0 \mathrm{mg}$ of arsenic each day. The committee puts the maximum acceptable load at $0.05 \mathrm{mg} / \mathrm{kg}$ of body weight, and recommends that the maximum content of arsenic in food additives be $3 \mathrm{mg} / \mathrm{kg}$; for heavy metals they recommend $40 \mathrm{mg} / \mathrm{kg}$, and for lead $10 \mathrm{mg} / \mathrm{kg}$ in cases where the daily intake of the additive exceeds $1 \mathrm{~g}$.

In several cases a decision on the use of an additive has had to be deferred because of lack of data. Of the natural stabilizers, furcelleran and its salts could not be evaluated in the absence of toxicological data. Concerning carrageen and its salts, now used as food additives, toxicological data are inadequate to establish an acceptable daily intake, and the committee recommends that this information be made available within the next four years so that a decision may be taken on permission to continue the use of this substance. Information is also inadequate concerning those long established additives gum arabic, karaya, tragacanth and carob bean gum, although tentative specifications have been prepared. Details of all specifications will be given in monographs containing biological data and toxicological evaluation of the various additives, and the committee suggests that a decision to use a particular additive should only be taken after consulting the detailed monographs.

\section{Making Air Fresh}

"TAKE a deep breath and be sick" is a wry comment sometimes heard in the United States. In Britain, 